\title{
Linfoma não-Hodgkin de cordão espermático
}

\section{Non-Hodgkin's lymphoma of the spermatic cord}

Marcelo Wilson Rocha Almeida ${ }^{1}$; André Bauer Sica Diniz²; Gilca Costa Nachtigal ${ }^{3}$; Valéria Magalhães Jorge ${ }^{4}$; FÁBIO SILVEIRA DE OLIVEIRA ${ }^{5}$

\section{INTRODUÇÃO}

$\mathrm{O}$ linfoma não-hodgkin é uma doença maligna que pode virtualmente aparecer em qualquer região do corpo. O envolvimento no aparelho genito-urinário é incomum e, quando ocorre, o sítio mais frequente é o testículo (5\% dos (asos) $)^{1}$.

Os tumores do cordão espermático são incomuns. Destes, o linfoma primário é um dos mais raros ${ }^{1}$. Na atualidade existem 14 casos publicados ${ }^{1-4}$. El Badawi \& AlGhorab² revisaram 387 casos de tumores primários do funículo espermático e descreveram apenas seis $(1,6 \%)$ como linfomas. Desde então, apenas oito (oito) outros casos foram relatados ${ }^{1}$.

Clinicamente apresenta-se como uma tumoração indolor da região inguinal que normalmente é confundido com uma hérnia inguino-escrotal, sendo o diagnóstico de neoplasia freqüentemente um achado trans-operatório ${ }^{3}$.

Este estudo apresenta um novo caso de linfoma de cordão espermático, tratado com orquiectomia radical e quimioterapia adjuvante, com remissão completa da doença. Hoje se encontra com quatros anos e meio de seguimento, sem evidência clínica recidiva, pois os exames de imagem apresentam-se normais.

\section{RELATO DO CASO}

Paciente masculino, branco, 71 anos, procurou o Serviço de Urologia com queixa de abaulamento em região inguinal esquerda, indolor, com seis meses de evolução. Ao exame apresentava massa de consistência endurecida, indolor, localizada no trajeto inguinal esquerdo, aderida ao cordão espermático. Testículos normais à palpação. Negava história familiar de neoplasia.

A ultra-sonografia evidenciou massa paratesticular heterogênea, em topografia de cordão espermático, sem envolvimento de testículo ou epidídimo.

O paciente foi submetido à operação, com abordagem pela via inguinal esquerda, sendo evidenciada massa endurecida aderida ao cordão espermático com aproximadamente $4,5 \mathrm{~cm}$ de diâmetro longitudinal (Figura 1). Procedeu-se à orquiectomia radical com ligadura precoce do cordão espermático. O pós-operatório evoluiu sem intercorrências, tendo recebido alta no primeiro dia de pósoperatório.

O estudo anátomo-patológico confirmado por imuno-histoquímica revelou linfoma de funículo espermático, não-hodgkin, linhagem B, difuso e de grandes células (R.E.A.L.) com margens cirúrgicas livres sem envolvimento do testículo ou epidídimo (Figura 2).

Realizou-se investigação complementar com biópsia de medula óssea normal e tomografia computadorizada de tórax e abdome que não revelaram alterações.

O paciente foi encaminhado para quimioterapia adjuvante que foi realizada com Ciclofosfamida, Doxorrubicina, Vincristina e Prednisona (CHOP) com remissão completa da doença e atualmente encontra-se com quatros anos e meio de seguimento, sem evidência clínica de recidiva e com exames de imagens normais.

\section{DISCUSSÃO}

A revisão dos 14 casos de linfoma primário do funículo espermático relatados na literatura internacional mos-



Figura 1 - Visão macroscópica de massa envolvendo o cordão espermático.

Trabalho realizado no Serviço de Urologia da Santa Casa Misericórdia de Pelotas, RS, Brasil.

1. Residente de Cirurgia Plástica do Instituto Ivo Pitanguy- Rio de Janeiro - RJ-BR. 2. Urologista da Santa Casa. 3. Hematologista da Universidade Federal de Pelotas (UFPel)-RS-BR. 4. Patologista do Centro de Anatomia Patológica da Santa Casa de Misericórdia de Pelotas- RS-BR. 5. Acadêmico da Escola de Medicina da Universidade Federal de Rio Grande - RS-BR. 

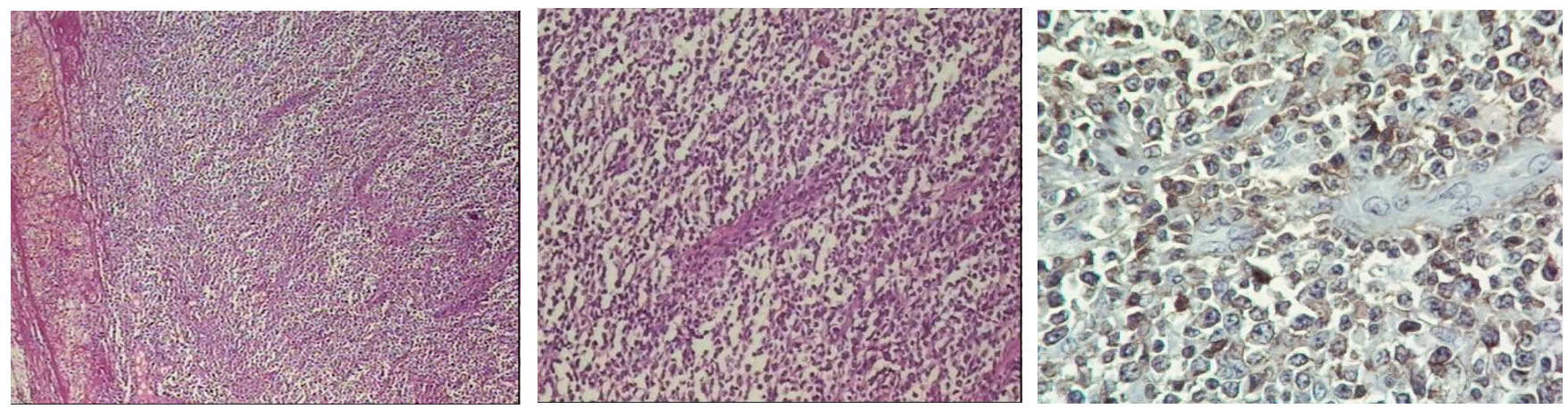

Figura 2 - (a). Infiltrado de pequenos linfócitos atípicos; (b). Detalhe. (c). Imuno-histoquímica evidenciando linfoma de funículo espermático, não-hodgkin, linhagem B, difuso e de grandes células (R.E.A.L.).

trou que geralmente estes se apresentam como uma tumoração indolor localizada na região inguinal ou na parte superior da bolsa testicular, sem envolvimento do testículo homolateral ${ }^{1,3,4}$. Dos 11 casos revisados por Moller, três foram diagnosticados primariamente como hérnia inguino-escrotal, sendo o diagnóstico de neoplasia um achado trans-operatório.

O linfoma primário do funículo espermático acomete homens entre 20 e 89 anos $^{1,3}$ e o diagnóstico diferencial é feito com outros tumores benignos ou malignos da região inguino-escrotal, funiculites e criptorquidia ${ }^{3}$. Okabe et al revisando 14 casos verificaram que 12 estavam no estágio I, um no estágio II e um no estágio IV, sendo todos os linfomas não-hodgkin, linhagem B.
A ocorrência rara do linfoma do cordão espermático dificulta o seu estudo e o estabelecimento de uma padronização quanto ao tratamento. Sabe-se que quando tratados apenas com ressecção ou radioterapia isoladamente, mesmo num estágio inicial, apresentam mal prognóstico, provavelmente devido à micro metástases indetectáveis ${ }^{3,4}$. Com base nestas informações parece que a ressecção, associada à quimioterapia e, nos casos mais avançados, a radioterapia adjuvante são uma boa opção ${ }^{1}$, porém, a escolha do tratamento deve ser individualizada de acordo com o estágio da doença, a histopatologia do tumor e as condições clínicas do paciente.

\title{
A B S T R A C T
}

\begin{abstract}
Non-Hodgkin's lymphoma of the spermatic cord are rare. There is the registration of 14 (fourteen) cases of spermatic cord lymphoma in the literature, all treated with radical orchiectomy with or without radiotherapy. The adjuvant chemotherapy still is not a consensus, therefore the therapy must be individualized and applied according to the stage of the disease. The present study report a new case of primary non-Hodgkin's lymphoma of the spermatic cord treated with radical orchiectomy through inguinal via with precocious ligature of the spermatic cord and adjuvant chemotherapy. Presently found with 2 and a half years of follow-up without recidivation clinical evidence, as the image exams show to be normal.
\end{abstract}

Key words: Lymphoma; spermatic cord; Non-Hodgkin lymphoma.

\section{REFERÊNCIAS}

1. Okabe M, Kurosawa M, Suzuki S, Kondo T, Choi GH, Hatanaka K et al. Primary lymphoma of spermatic cord. Leuk Lymphoma. 2001; 40(5-6):663-6.

2. El-Badawi AA, Al-Ghorab MM. Tumors of the spermatic cord: a review of literature and a report of a case of lymphangioma. J Urol. 1965; 94(4):445-50.

3. Møller MB. Non-Hodgkin's lymphoma of the spermatic cord. Acta Haematol. 1994; 91(2):70-2.

4. Lands RH. Non-Hodgkin's lymphoma originating in the spermatic cord. South Med J. 1996; 89(3):352-3.
Recebido em 02/05/2006

Aceito para publicação em 02/06/2006

Conflito de interesse: nenhum

Fonte de financiamento: nenhuma

\section{Como citar este artigo:}

Almeida MWR, Diniz ABS, Nachtigal GC, Jorge VM, Oliveira FS. Linfoma não-Hodgkin de cordão espermático. Rev Col Bras Cir. [periódico na Internet] 2009; 36(5). Disponível em URL: http://www.scielo.br/rcbc

\section{Endereço para correspondência:}

Marcelo Wilson Rocha Almeida.

E-mail: marcelowralmeida@yahoo.com.br 